\title{
Sternal Mass as First Presentation of Follicular Thyroid Carcinoma
}

Onimode Yetunde $\mathbf{A}^{1,2^{*}}$, Adedapo Kayode $\mathbf{S b}^{3}$ and Osifo Bola $\mathbf{O}^{1,2}$

${ }^{1}$ Department of Radiotherapy, College of Medicine, University of Ibadan, Oyo State, Nigeria

${ }^{2}$ Department of Nuclear Medicine, University College Hospital, Ibadan, Oyo State, Nigeria

${ }^{3}$ Department of Chemical Pathology, College of Medicine, University of Ibadan, Oyo State, Nigeria

*Corresponding author: Onimode Yetunde A, Department of Radiotherapy, College of Medicine, University of Ibadan, Oyo State, Nigeria, Tel: +2347087821065; Email: yately_md@yahoo.com

Received date: Sep 10, 2014, Accepted date: Oct 22, 2014, Publication date: Oct 27, 2014

Copyright: (c) 2014 Yetunde AO, et al. This is an open-access article distributed under the terms of the Creative Commons Attribution License, which permits unrestricted use, distribution, and reproduction in any medium, provided the original author and source are credited.

\begin{abstract}
Thyroid carcinoma is the commonest endocrine malignancy, although less than $1 \%$ of all cancers. Osseous metastases are more often associated with the follicular type of thyroid carcinoma. Fewer than $5 \%$ of patients present with distant metastases. We present a case of sternal metastasis being the first observed feature of follicular thyroid carcinoma.
\end{abstract}

A 62-year old female developed a painless nodule over her sternum, which progressively enlarged over approximately two years. Patient was seen at another medical facility, where histology of the mass revealed metastatic follicular thyroid carcinoma. Subsequent left thyroid lobectomy confirmed follicular thyroid cancer on histology. She was treated with $100 \mathrm{mCi}$ of radioiodine l-131 (RAI), and suppressive L-thyroxine therapy implemented thereafter.

However, the sternal mass recurred seven months post-sternectomy. She patient was then referred to our facility. The mass was deemed inoperable. Thus, she was treated with $200 \mathrm{mCi}$ of RAl under steroid cover. The RAI therapy scan showed intense uptake in the sternal mass as well as less prominent thyroid bed uptake. The patient has since been referred for external beam radiation therapy.

The clinician is reminded of one of the modes of presentation of thyroid cancer. Thyroid cancer has been deemed an indolent tumour but may also exhibit aggressive behaviour as occurred in this patient. This case also buttresses the importance of early biopsy and diagnosis in the investigation of tumours.

Keywords: Follicular thyroid cancer; Sternal metastasis; Nuclear medicine; Radioiodine I-131

\section{Introduction}

Thyroid carcinoma is the commonest endocrine malignancy, although less than $1 \%$ of all cancers [1]. The papillary subtype of thyroid cancer is commoner; however, follicular thyroid carcinoma is characteristically commoner in iodine-deficient regions of the world [2]. The incidence in Nigeria is estimated as $0.5 \%$, with a prevalence rate of $0.4 \%$. West African incidence and mortality rates for the cancer are $0.8 \%$ and $0.6 \%$, respectively $[3,4]$. Haematogenous dissemination is one of the acknowledged routes of spread of differentiated thyroid carcinoma. Osseous metastases are more often associated with follicular thyroid carcinoma [5]. Fewer than 5\% of patients present with distant metastases [6,7]. We present a case of skeletal metastasis being the first observed feature of follicular thyroid carcinoma.

\section{Patient findings}

A 62-year old female initially developed a painless nodule over her sternum, which progressively evolved to become a large mass "the size of an orange" over approximately two years. The mass measured 10.5 x $6.5 \times 6.3 \mathrm{~cm}$ on CT scan and was described as a heterogeneously enhancing lesion eroding the sternum. A hypodense nodule was also observed in the left thyroid lobe, and tracheal displacement to the right.

She eventually had a sternectomy two years after mass was first observed, with histology revealing metastatic follicular thyroid carcinoma. She subsequently had a left lobectomy of the thyroid, following diagnostic work-up. Histology of the surgical specimen also confirmed follicular thyroid cancer. At a private facility, $100 \mathrm{mCi}$ of radioiodine (RAI) I-131 was administered to the patient. Suppressive therapy with daily dose of 100 micrograms of L-thyroxine was also implemented post-RAI.

Seven months post-sternectomy, the anterior chest mass recurred as a larger lesion. The patient presented to our facility where a large ovoid sternal mass measuring $21.5 \mathrm{~cm} \mathrm{x} 22 \mathrm{~cm}$ was observed (Figure 1). She had a diagnostic scan (Figure 2), which depicted residual thyroid uptake as well as intense uptake in the sternal mass. A repeat diagnostic CT scan described significant left cervical, prevascular and right hilar lymphadenopathy. A sub-centimetre pulmonary nodule was also visualized in the anterior segment of the left lung. The recurrent sternal mass was deemed inoperable by the Endocrine surgical team. Thus, the management plan was to proceed with radioiodine-131 therapy (RAI) followed by external beam radiotherapy (EBRT). 
Citation: Yetunde AO, Adedapo Kayode Sb, Osifo Bola O (2014) Sternal Mass as First Presentation of Follicular Thyroid Carcinoma. J Nucl Med

Page 2 of 3

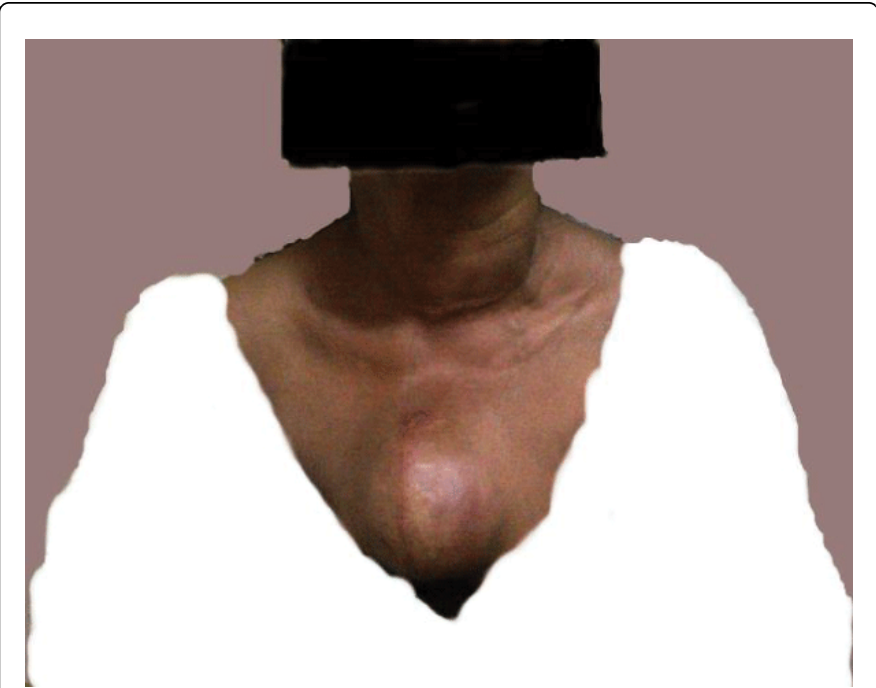

Figure 1: Recurrent sternal mass as seen at presentation at our facility.

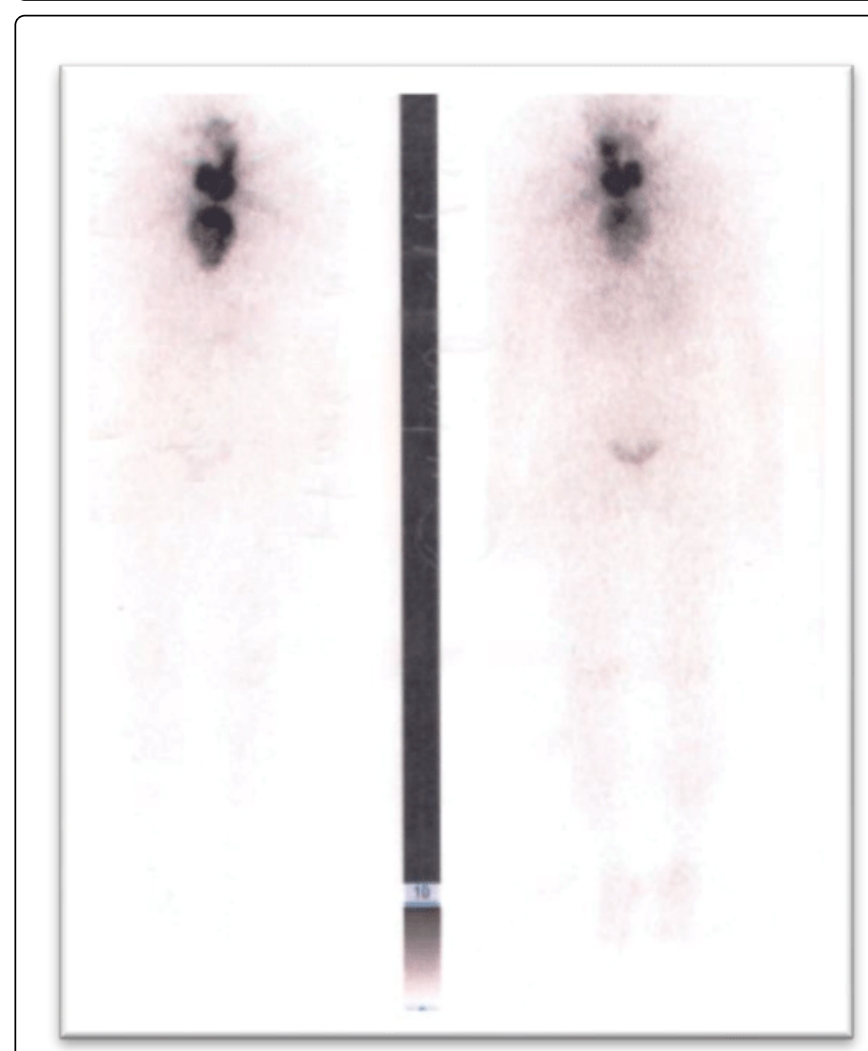

Figure 2: Diagnostic I-131 scan $(5 \mathrm{mCi})$ : residual thyroid and sternal uptake.

Following adequate preparation, the patient received $200 \mathrm{mCi}$ of I-131 under steroid cover. By this time, the mass had increased in size to $23 \mathrm{~cm} \mathrm{x} 26 \mathrm{~cm}$. It is of interest to note that following RAI ablation, her radiation levels did not diminish as rapidly as expected despite liberal fluid intake as tolerated. She was eventually deemed fit for public interaction twelve days post-RAI instead of the usual three to four days. The therapy scan (Figure 3) showed intense uptake in the sternal mass as well as less prominent thyroid bed uptake. Post-RAI therapy haematology profile was satisfactory. The patient has since been referred for EBRT.

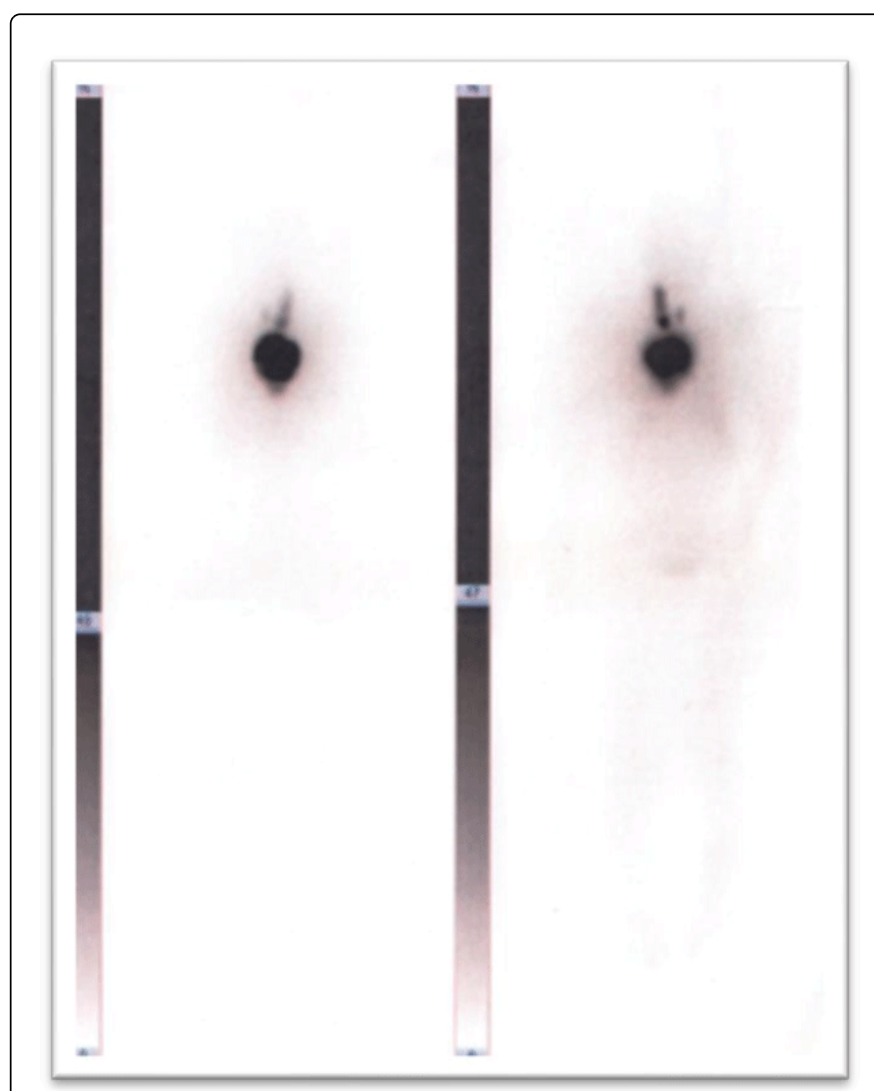

Figure 3: Therapy I-131 scan $(200 \mathrm{mCi})$ : less prominent thyroid uptake and intense uptake in sternal mass.

\section{Discussion}

Follicular thyroid carcinoma is known to cause distant metastases most commonly to the lungs and skeleton, less commonly to the brain and the liver [8]. The frequency of skeletal metastases has been quoted as being as high as $23 \%$ in other reports [9,10]. At first presentation, fewer than $5 \%$ of patients have distant metastases [6]. Goffredo et al [11] also described the frequency of osseous metastases at presentation in 59,809 thyroid cancer patients as $2.2 \%$. They are commoner in male than in female patients, and in older patients. Bone metastases confer poorer prognosis on affected patients as they are usually not cured with RAI therapy $[12,13]$. Durante et al. [14] described metastases as being commoner in follicular than in papillary thyroid cancer; $7-28 \%$ vs. $1.4-7 \%$, respectively.

Compared to radioiodine or FDG PET/CT imaging, planar bone scintigraphy (BS) has been described as being less sensitive in detecting skeletal metastases [15]. However, both osteoblastic and osteolytic metastases may develop from thyroid cancer, and the bone scan is notorious as being less sensitive for lytic bone lesions unless they are large enough or aggressive. Positron-emission tomography (PET) imaging with F-18 fluoride or F-18 fluorodeoxyglucose (FDG) 
[16] is another Nuclear Medicine option, with its improved spatial resolution and sensitivity [17]. The latter may also display soft tissue metastases. In such instances, anatomical radiological imaging is complementary. This patient had radioiodine imaging which showed primary lesion and metastases. Complementary BS was not performed prior to RAI therapy as it was perceived that the I-131 scan would suffice, but BS will be also be implemented in patient's follow-up plan.

Treatment options for skeletal metastases are surgical resection, external beam radiotherapy, bisphosphonate therapy, tumour embolization, palliation with analgesia and radiotracers for those lesions recalcitrant to analgesia. Bone metastases are quite difficult to cure, as bone tissue itself is radio-resistant. Thus, these measures are palliative. The aggressive nature of the lesion has also raised the possibility of chemotherapy as an option for therapy.

The delay in return of radiation levels to normal in the patient is probably due to retention of radiotracer in the large mass. Her renal function had been confirmed as normal prior to therapy.

The patient was treated with a second dose of $200 \mathrm{mCi}$ and later referred for EBRT.

\section{Conclusion}

The clinician is reminded of one of the modes of presentation of thyroid cancer. Thyroid cancer has been deemed an indolent tumour but may also exhibit aggressive behaviour as occurred in this patient. The importance of early biopsy and diagnosis in tumour investigation is once again buttressed. As well, this case illustrates the advantage that SPECT/CT would have contributed to patient's imaging.

\section{Author Disclosure Statement}

No competing financial interests exist.

\section{References}

1. Langsteger W, Költringer P, Wolf G, Dominik K, Buchinger W, et al. (1993) The impact of geographical, clinical, dietary and radiationinduced features in epidemiology of thyroid cancer. Eur J Cancer 11: 1547-1553.

2. Lohrs U, Permanetter W, Spelsberg F, Beitinger M (1977) Investigation of frequency and spreading of different histological types of thyroid cancer in an endemic goitre region. Verhandl Dtsch Ges Pathol 61: 268-274

3. Ferlay J, Soerjomataram I, Ervik M, Dikshit R, Eser S et al (2013) GLOBOCAN 2012 v1.0, Cancer Incidence and Mortality Worldwide:
IARC Cancer Base No. 11 [Internet].Lyon, France: International Agency for Research on Cancer.

4. Bray F, Ren JS, Masuyer E, Ferlay J. (2013) Estimates of global cancer prevalence for 27 sites in the adult population in 2008. Int J Cancer 132: 1133-1145.

5. Yanagawa J, Abtin F, Lai CK, Yeh M, Britten CD, et al. (2009) Resection of thyroid cancer metastases to the sternum. J Thoracic Oncology 4: 1022-1025.

6. Hoie J, Stenwig AE, Kullmann G, Lindegard M (1988) Distant metastases in papillary thyroid cancer. A review of 91 patients. Cancer 61: 1-6.

7. Schlumberger M, Tubiana M, De Varthaire F, Hill C, Gadret P, et al (1986) Long-term results of treatment of 283 patients with lung and bone metatases from differentiated thyroid carcinoma. J Clin Endocrinol Metab 63: 960-967.

8. Ell PJ, Gambhir SS (2004) Nuclear medicine in clinical diagnosis and treatment. Churchill Livingstone, Philadelphia.

9. Tickoo SK, Pittas AG, Adler M, Fazzari M, Larson SM, et al. (2000) Bone metastases from thyroid carcinoma. A histopathologic study with clinical correlates. Arch Pathol Lab Med 124: 1440-1447.

10. Zettinig G, Fueger EJ, Passler C, Kaserer K, Pirich C, et al. (2002) Longterm follow-up of patients with bone metastases from differentiated thyroid carcinoma - surgery or conventional therapy? Clinical Endocrinology 56: 377-382.

11. Goffredo P, Sosa JA, Roman SA (2013) Differentiated thyroid cancer presenting with distant metastases: a population analysis over two decades. World J Surg 37: 1599-1605.

12. Mishra A, Mishra SK, Agarwal A, Agarwal G, Agarwal SK (2001) Surgical treatment of sternal metastases from thyroid carcinoma: report of two cases. Surg Today 31: 799-802.

13. Ishinaga H, Miyamura T, Tenpaku H, Takeuchi K (2013) Metastasis of thyroid cancer to the sternum after total thyroidectomy and laryngectomy. Case Reports in Surgery: 346246.

14. Durante C, Haddy N, Baudin E, Leboulleux S, Harl D, et al. (2006) Longterm outcome of 444 patients with distant metastases form papillary and follicular thyroid carcinoma: benefits and limits of radioiodine therapy. J Clin Endocrinol Metab 9: 2892-2899.

15. Zhong-Ling Q, Yan-Li X, Hong-Jun S, Quan-Yong L (2012) Comparison of the diagnostic and prognostic values of $99 \mathrm{mTc}-\mathrm{MDP}$-planar bone scintigraphy, 131I-SPECT/CT and 18F-FDG-PET/CT for the detection of bone metastases from differentiated thyroid cancer. Nucl Med Comm 33: 1232-1242.

16. Cook GJ, Houston S, Rubens R, Maisey MN, Fogelman I (1998) Detection of bone metastases in breast cancer by 18FDG PET: differing metabolic activity in osteoblastic and osteolytic lesions. J Clin Oncol 16: 3375-3379.

17. Özülker T, Uzun A K, Özülker F, Özpaçaci T (2010) Comparison of 18FFDG PET/CT with 99mTc-MDP bone scintigraphy for the detection of bone metastases in cancer patients. Nucl Med Comm 31: 597-603. 